\title{
RESIDÊNCIA ESTUDANTIL: QUAL É A SUA EFICÁCIA NA CONCEPÇÃO DO ESTUDANTE RESIDENTE NO IFCE DO CAMPUS CRATO?
}

\author{
Maria Lucileide Costa Duarte ${ }^{1}$, Zósimo Mota Queiroz ${ }^{1}$, Maria Albaneide Fortaleza ${ }^{2}$
}

${ }^{1}$ Instituto Federal de Educação, Ciência e Tecnologia do Ceará (IFCE) Campus de Crato

${ }^{2}$ Escola de Ensino Médio de Campos Sales-CE

<lucileideduarte@hotmail.com><zosimomqueiroz@hotmail.com> <albafortcs@yahoo.com.br>

DOI: $10.21439 /$ conexoes.v11i4.900

\begin{abstract}
Resumo. Esse estudo visa investigar a eficácia da residência estudantil na concepção do estudante residente no IFCE campus Crato/CE. Trata-se de uma pesquisa de campo, usando como metodologia a aplicação de um questionário para 66 discentes contemplados com o serviço de moradia, correspondendo a 43,42\% do universo, no período de 02 e 03 de março de 2015. A partir da análise dos resultados, observamos que 94\% afirmaram que a residência estudantil contribui tanto para a permanência no curso, como também, para melhor desempenho escolar. Outro aspecto a ser observado, refere-se ao atendimento às necessidades estudantis, onde $64 \%$ afirmaram que suas necessidades são atendidas parcialmente e os demais $36 \%$ revelaram ter suas necessidades totalmente supridas. Os discentes ressaltaram a necessidade de inserção da rede wifi na área da residência, correspondendo a 25\%. Por fim, entendemos que este estudo é um relevante instrumento para a gestão institucional, uma vez que apresenta dados que reforçam o trabalho interdisciplinar de acompanhamento sociopedagógico dos discentes atendidos pelo serviço de moradia.
\end{abstract}

Palavras-chaves: Educação Profissional. Instituto Federal de Educação. Internato.

\begin{abstract}
This study aims to investigate the students residence efficacy in the conception of the resident student at the IFCE campus Crato. This is a field research, using as methodology, the application of a questionnaire for 66 students awarded with the housing service, corresponding to $43.42 \%$ of all of them, in the period from 2 to 3 of March 2015. From the analysis of the results, we noticed that $94 \%$ said that the student residence contributes both to stay on the course, as well as a better school performance. Another aspect to be noted, refers to the assistance of the students' needs, in which $64 \%$ of the students said that their necessities were partially met and the remaining $36 \%$ said that their necessities were totaly met. The students emphasized the insertion necessity of wifi network in the residence areas, corresponding to $25 \%$. Finally, we believe that this study is an important tool for a institutional management, since it presents data that reinforces the interdisciplinary work of socio-pedagogical monitoring of students attended by the housing service.
\end{abstract}

Keywords: Teaching. Human formation. Self-care. Contemporaneity. Teaching. Human formation. Selfcare. Contemporaneity. 


\section{INTRODUÇÃO}

Ao analisarmos a história, verificamos que na década de 30 , a residência estudantil e os restaurantes universitários foram mecanismos de apoio para os estudantes no Brasil. Durante o período de 34 a 67, os estabelecimentos federais de ensino profissional agrícola, ofereciam assistência integral aos alunos, a qual compreendia a moradia, alimentação, assistência médica e odontológica e outros bens e serviços (CONCEIÇÃO, 2010).

A partir da implantação do Programa Nacional de Assistência Estudantil (PNAES), pela Portaria $n^{\circ} 39$, de 12 de dezembro de 2007 (BRASIL, 2007) e posteriormente, com a sua regulamentação, através do Decreto $\mathrm{n}^{0} 7.234$, de 19 de julho de 2010 (BRASIL, 2010), o IFCE campus Crato implementou algumas de suas ações, inclusive o auxílio moradia. Paralelo a esse auxílio, permaneceu o serviço de residência, pois já existia na Instituição quando se tratava da Escola Agrotécnica Federal de Crato - CE. Considerando que o PNAES tem como finalidade a ampliação de condições de permanência dos jovens na educação superior pública federal (BRASIL, 2010), como também dos discentes dos Institutos Federais, surgiu o interesse em investigar se o serviço de moradia apresenta eficácia, na visão dos estudantes usuários dessa modalidade.

Atualmente, o IFCE campus Crato oferta os cursos: Técnico em Agropecuária integrado ao ensino médio; Técnico em Agropecuária pós-médio (subsequente); Técnico em Informática para internet integrado ao ensino médio, Técnico em Agronegócio na modalidade à distância; Bacharelado em Zootecnia e Bacharelado em Sistemas de Informação, salientando-se que o serviço de residência é direcionado para os discentes de nível médio e de sexo masculino.

Diante do contexto explanado, o presente trabalho tem por objetivo apresentar a concepção do aluno residente acerca da eficácia da assistência estudantil, particularmente no que se refere às ações voltadas para a moradia estudantil do IFCE campus Crato - $\mathrm{CE}$. A temática apresentada é de relevante importância, pois a moradia é uma das ações primordiais do Programa Nacional de Assistência Estudantil (PNAES), sendo considerada como um mecanismo para apoiar o estudante, em condições socioeconômicas desfavoráveis, oriundo de outros locais e que pretende dar continuidade aos seus estudos.

Considerando os aspectos mencionados, o artigo discutirá os seguintes pontos: inicialmente, a educação profissional, um breve histórico do Instituto Federal do campus Crato - CE e o internato. Em seguida, serão detalhados os materiais e métodos utilizados, bem como os resultados e discussões encontrados. E, por fim, a conclu- são.

\section{REFERENCIAL TEÓRICO}

\subsection{A Educação Profissional}

A Rede Federal de Educação Profissional inicia no governo do Presidente Nilo Peçanha, no ano de 1909, quando foram criadas 19 escolas de Aprendizes e Artífices, através do Decreto 7.566. As considerações iniciais expressas nesse instrumento, descreviam:

[...] que o augmento constante da população das cidades exige que se facilite às classes proletarias os meios de vencer as dificuldades sempre crescentes da lueta pela existencia: que para isso se torna necessario, não só habilitar os filhos dos desfavorecidos da fortuna com o indispensavel preparo technico e intelectual, como fazê-los adquirir habitos de trabalho proficuo, que os afastara da ociosidade ignorante, escola do vicio e do crime; que é um dos primeiros deveres do Governo da Republica formar codadões uteis à Nação (BRASIL 1996).

Até a década de 1930, o Brasil se manteve agroexportador e a educação era de cunho elitista, voltada para as áreas de letras e humanidades. E por se tratar de um país essencialmente agroexportador, era admissível o nível de escolaridade baixo da população (WERMELINGER; MACHADO; AMÂNCIO FILHO, 2007).

No ano de 1930, àquelas Escolas deram lugar aos Liceus Profissionais e, em 1942, às Escolas Industriais e Técnicas. Posteriormente, essas escolas foram transformadas em autarquias com o nome de Escolas Técnicas Federais, no ano de 1959. Em 1978, com a Lei ${ }^{\circ}$ 6.545, três Escolas Técnicas, nos Estados do Paraná, Minas Gerais e Rio de Janeiro, foram transformadas em Centros Federais de Educação Tecnológica (CEFETs) (OTRANTO, 2011).

Através da Lei Federal $n^{0} 8.948 / 94$, foi institudo o Sistema Nacional de Educação Tecnológica, que transformou as antigas Escolas Técnicas em Centros Federais de Educação Tecnológica e a Lei Federal $n^{\circ}$ 8.731/93, que transformou as Escolas Agrotécnicas em Autarquias Federais de Regime Especial (PELLA, 2005).

Dois anos depois, em 20 de novembro de 1996, foi sancionada a Lei $n^{\circ} 9.394$ considerada como a $2^{\text {a }}$ Lei de Diretrizes e Bases da Educação (LDB), que dispõe sobre a educação profissional em um capítulo separado da educação básica (BRASIL, 1996).

Nessa década, a globalização se apresenta de forma perversa e violenta acelerando processos de precarização, terceirização, Estado mínimo, supressão de milhares de postos de trabalho. $\mathrm{O}$ sistema produtivo passa a exigir um novo perfil de trabalhador mais qualificado e mais eficiente. Dessa forma, passa a ser exigido da escola a formação de especialistas habilidosos e competentes em suas 
ocupações no mercado de trabalho. É nesse cenário que ocorre a reforma da educação profissional.

Em meio a esses fatos, em abril de 1997, o governo baixou o Decreto $n^{\circ} 2.208$ que proibia a integração entre a formação geral e a profissional nos cursos técnicos. Assim, privilegia-se uma formação restrita e direcionada para ocupações no mercado de trabalho. Podemos perceber a existência de duas vertentes na educação: uma voltada para a formação de cunho mais geral com direito ao nível superior e outra de formação estritamente profissional e sem direito ao acesso à graduação (FEITOSA 2010).

No ano de 2002, reacende a esperança da população com a eleição do presidente Luiz Inácio Lula da Silva no que se refere aos rumos da educação, sobretudo a educação profissional. Revoga-se o Decreto $n^{0} 2.208 / 97$ e publica-se o Decreto $n^{0} 5.154$, em 23 de julho de 2004, que oferecia a educação profissional e o ensino médio de forma integrada, ou seja, as escolas voltaram a ofertar a educação profissional e o ensino médio, utilizando a mesma infraestrutura, no mesmo turno/escola com os mesmos docentes (FEITOSA, 2010).

O projeto de democratização da educação brasileira continuou no governo daquele presidente, através da Expansão da Rede Federal de Educação Profissional e Tecnológica. Em 2008, universidades, as 07 escolas técnicas, 39 escolas agrotécnicas, 75 Unidades Descentralizadas de Ensino (UNEDs) e os 31 Centros de Educação Tecnológica (CEFETs) tornaram-se Institutos Federais (SOUSA 2013).

Sobre essas Instituições, Otranto (2011) chama a atenção de sua estrutura diferenciada e expressa que “ [...]Os IFs sintetizam, hoje, a expressão maior da atual política pública de educação profissional brasileira [...]" (OTRANTO, 2011, p. 11-12) e que as mudanças produzidas nas instituições precisam ser acompanhadas de perto. Sobre esse assunto, Pacheco (2011) menciona que essas Instituições "são a síntese daquilo que de melhor a Rede Federal construiu ao longo de sua história [...]" (PACHECO, 2011, p. 11)

O IFCE campus Crato - CE está incluso nessa rede educacional e, por isso, faremos, em seguida, um breve apanhado histórico a seu respeito.

\subsection{Instituto Federal de Educação, Ciência $e$ Tecnologia- campus Crato}

O Plano de Desenvolvimento Institucional 2014-2018, descreve que a Escola Agrotécnica Federal de Crato, foi criada a partir de um convênio celebrado entre a União e o município de Crato. Em 10 de abril de 1954, foi assinado o termo de instalação dessa Escola vinculada à Superin- tendência do Ensino Agrícola e Veterinário (SEAVE) do Ministério da Agricultura. As atividades se iniciaram com a implantação do curso de Tratorista (FEITOSA, 2010).

Desse período, até o ano de 2009, quando se tornou campus do IFCE, diversas reestruturações políticoadministrativas do Governo Federal provocaram mudanças nas vinculações dessa Escola às Secretarias dos Ministérios. Através do Decreto 60.731, de 19 de maio de 1967, o Colégio Agrícola de Crato foi transferido do Ministério da Agricultura para o Ministério da Educação e Cultura. A SEAVE por sua vez, foi transformada em Diretoria do Ensino Médio (IFCE, 2013).

Em seu percurso histórico, essa Escola esteve vinculada a diversas Secretarias do Ministério da Educação que nasceram e se extinguiram por razões administrativas. Vinculou-se à Coordenação Nacional de Ensino Agrícola, à Coordenação Nacional de Ensino Agropecuário, à Secretaria de Ensino de $2^{\circ}$ Grau e, atualmente, por ser campus do IFCE está vinculado à Secretaria de Educação Profissional e Tecnológica (SETEC). As denominações dessa unidade também passaram por alterações (IFCE, 2013).

Além dos cursos ofertados, o regime escolar do campus Crato/CE se apresenta de três formas: a residência estudantil para os alunos de nível médio de sexo masculino, semirresidência e o regime externo, em que o discente deixa de permanecer no espaço estudantil após o turno de aula.

Acreditamos que a residência estudantil seja um elemento atrativo para os estudantes inseridos em um contexto familiar sob condições socioeconômicas desfavoráveis, oriundos de municípios distantes ou circunvizinhos da sede do campus, para dar continuidade a seus estudos.

\subsection{Regime de Internato/Moradia Estudantil}

O internato ou a moradia estudantil é uma das ações da assistência estudantil, a qual tem se consolidado por meio do Programa Nacional de Assistência Estudantil (PNAES), através da Portaria Normativa no 39, de 12 de dezembro de 2007, do Ministério da Educação e de sua regulamentação pelo Decreto 7.234 , de 19 de julho de 2010.

É um serviço ofertado por algumas instituições e se apresenta como uma alternativa de permanência do estudante, onde os discentes vivem com seus pares, obtendo o direito de permanência durante os dias de aula e, se necessário, em finais de semana e feriados. Em se tratando da história da vida escolar na Idade Média, nada (a) narra que os alunos, independentemente da idade, eram abandonados a si mesmos. Alguns, raramente, moravam com seus pais. Uma outra modalidade de convivência era: 


\begin{abstract}
[...] em regime de pensão, quer na casa do próprio mestre, quer na casa de um padre ou cônego, segundo as condições fixadas por um contrato semelhante ao contrato de aprendizagem. Estes últimos eram os mais vigiados, ou ao menos os mais seguidos. Pertenciam a uma casa, à família do clérigo ao qual haviam sido confiados, e nesse caso havia uma espécie de compromisso entre a educação pela aprendizagem, $[\ldots]$ e a educação escolar de tipo moderno. Essa era a única forma de internato conhecido (NADA a p.167-168).
\end{abstract}

Esse mesmo autor, faz menção também ao surgimento da disciplina escolar, que teve origem na disciplina eclesiástica ou religiosa, como um instrumento mais de aperfeiçoamento moral e espiritual do que um mecanismo de coerção. A disciplina fez parte da rotina dos colégios, bem como das pensões particulares onde havia alunos residentes. Dessa forma:

\begin{abstract}
Os mestres tenderam a submeter o aluno a um controle cada vez mais estrito, no qual as famílias, a partir do fim do século XVII, cada vez mais passaram a ver as melhores condições de uma educação séria. Chegou-se a aumentar os efetivos outrora excepcionais dos internos, e a instituição ideal do século XIX seria o internato, quer fosse um liceu, um pequeno seminário, um colégio religioso ou uma escola normal (NADA a p.191).
\end{abstract}

Tratando-se do termo disciplina, Foucault (2009), destaca que os processos disciplinares, existiam há muito tempo nos conventos, nos exércitos, nas oficinas, porém tornaram-se fórmulas gerais de dominação no decorrer dos séculos XVII e XVIII. Para esse autor, “a disciplina 'fabrica' indivíduos; ela é a técnica específica de um poder que toma os indivíduos ao mesmo tempo como objetos e como instrumentos de seu exercício" (FOUCAULT 2009, p.164).

Para esse autor, a disciplina em primeiro lugar, resulta na distribuição dos indivíduos em um determinado espaço. Utiliza várias técnicas, como colégios e quartéis, por exemplo (FOUCAULT, 2009). Um mecanismo pode ser o internato.

Para compreender essa modalidade de convivência, faz-se necessário entendermos a definição de instituição total, expressa por Goffman (2008), que a define como:

\begin{abstract}
[...] um local de residência e trabalho onde um grande número de indivíduos com situação semelhante, separados da sociedade mais ampla por considerável período de tempo, levam uma vida fechada e formalmente administrada [... um híbrido social, parcialmente comunidade residencial, parcialmente organização formal [...] são as estufas para mudar pessoas, cada uma é um experimento natural sobre o que se pode fazer ao eu. [GOFFMAN 2008. p.11-22).
\end{abstract}

Acerca desse assunto, o autor expõe considerações que revestem a instituição total, tais como a totalidade. Isto é, todos os aspectos da vida são realizados no mesmo espaço e sob a única autoridade; a segregação, uma vez que no interior do internato há divisão básica entre o grupo que controla e outro que é controlado; atividades coletivas e iguais para todo o grupo e a normalização, isto é, a existência do plano único para atender aos objetivos oficiais da instituição (BARROSO, 2008).

Em alusão ao internato escolar agrícola, as instituições federais de ensino profissional do Brasil, o desenvolveram no período de 1934 a 1967, tendo como responsável o Ministério da Agricultura. Os internos tinham direito à política assistencial integral que possibilitava a viabilização de seus estudos. No dizer de Conceição (2010. p.81), "esse tipo de internato rural existiu para atender às razões práticas dos estabelecimentos de ensino agrícola [...]", pois estavam inseridos no campo e contemplavam a população pobre que buscava o ensino nessas instituições.

No ano de 1967, com a reforma administrativa dos Ministérios, o ensino agrícola foi absorvido pelo Ministério da Educação e Cultura (MEC). O MEC ao assumir o ensino agrícola através da Diretoria de Ensino Agrícola (DEA), implantou determinadas políticas, no sentido de formular a filosofia desse ensino. Foi instituída, assim, a metodologia do sistema escola-fazenda que se baseou no princípio "aprender a fazer e fazer para aprender" (SOBRAL, 2009).

Em 2008, através da Lei no 11.892 de 30 de dezembro, as escolas agrotécnicas foram transformadas em Institutos Federais de Educação, Ciência e Tecnologia iniciando a nova organização e gestão, sem excluir a oferta e objetivo do internato.

Convém mencionar, que mesmo a Escola Agrotécnica Federal de Crato - CE tendo se transformado em IFCE, a residência estudantil se manteve na estrutura da Instituição. Antes do Programa Nacional de Assistência Estudantil (PNAES), esse equipamento já atendia discentes de vários municípios. No mês de março de 2015, período da pesquisa de campo, a residência que tem capacidade para abrigar 160 estudantes, encontrava-se com 152, por motivos diversos.

\section{METODOLOGIA}

A pesquisa desenvolvida é descritiva, pois visa “ a descrição das características de determinada população ou fenômeno ou o estabelecimento de relações entre variáveis" (GIL, 1994, p.45). Trata-se de um estudo que se debruça em um levantamento bibliográfico utilizando livros, artigos científicos, dissertações, documentos oficiais para subsidiar o referencial teórico.

A pesquisa de campo desenvolveu-se através da distribuição de um questionário, que para Gil (1994, p.124), 

CRATO?

esse instrumento "é uma técnica de investigação composta por um número mais ou menos elevado de questões apresentadas por escrito às pessoas, tendo por objetivo o conhecimento de opiniões, crenças, sentimentos, interesses $[\ldots]$..."

O preenchimento dos questionários ocorreu nos dias 02 e 03 de março de 2015, na própria residência estudantil. No ato da entrega do instrumento, explicamos ao público-alvo os motivos pelos quais o recurso seria aplicado e de sua importância para o desenvolvimento da Instituição. Não seria obrigatório seu preenchimento. Todos ficariam à vontade para oferecer suas contribuições para esse trabalho.Os participantes não precisariam se identificar, pois o anonimato seria preservado.

Após a coleta dos dados, procedemos com a análise por meio da tabulação manual, sendo a anotação de cada valor com o registro de um traço, de maneira que se formasse um quadrado com o quinto traço no sentido transversal. Após esse procedimento, realizamos a análise estatística buscando respostas para o problema proposto pelo estudo.

\section{RESULTADOS E DISCUSSÕES}

Responderam ao questionário 66 alunos, de um total de 152 regularmente matriculados no IFCE campus Crato e que estão no regime de residência, correspondendo, assim, a $43,42 \%$ do total.

No que se refere ao local de origem, cinco cidades foram as mais citadas pelos estudantes, assim distribuídas: 17 (26\%) dos pesquisados revelaram ser de Porteiras - CE; 09 (14\%) de Exu - PE; 07 (11\%) de Jardim - CE; 06 (9\%) de Araripe - CE; 04 (6\%) de Santana do Cariri CE. A partir desses dados, percebemos que a procura pela residência estudantil no campus Crato se concentra em estudantes oriundos de regiões próximas ao município do Crato e pressupomos que exista uma disseminação de informações acerca da moradia entre os próprios estudantes da mesma cidade, como uma forma de se sentirem mais encorajados para enfrentar o desconhecido e ao mesmo tempo manter as relações sociais de suas origens.

Quanto ao Estado de origem, 49 (74\%) dos questionados são do Ceará; 15 (23\%) de Pernambuco e 02 (3\%) não responderam. Percebemos uma maioria expressiva de estudantes do Estado do Ceará, em detrimento de outros estados da federação, na busca de apoio para a moradia estudantil, a fim de dar continuidade aos seus estudos. Talvez essa pouca demanda dos outros Estados, esteja vinculada a ofertas de cursos variados em suas regiões locais.

Acerca da idade do aluno investigado até 31 de dezembro de 2015, 01 (2\%) tem 14 anos; 02 (3\%) 15 anos;
07 (11\%) 16 anos; 10 (15\%) 17 anos; 24 (36\%) 18 anos; $22(33 \%)$ acima de 18 anos. Devemos ressaltar que alguns desses estudantes participantes da pesquisa estão concluindo o ano letivo 2014 no mês de março de 2015, por conta da greve de servidores ocorrida em 2012. Dessa forma, pode ocorrer que alguns deles tenham a idade de 17 anos, uma vez que foi questionada qual a idade até 31 de dezembro do ano em curso. Outro aspecto que merece ser enfatizado é que parte desses discentes são do curso pós-médio (subsequente), os quais já concluíram o ensino médio e podem ter concluído aos 17 anos.

Os discentes participantes desse estudo estão matriculados nos cursos da seguinte maneira: 51 (77\%) no curso Técnico em Agropecuária integrado ao ensino médio; 09 (14\%) Técnico em Agropecuária pós-médio (subsequente) e 06 (9\%) Técnico em Informática para a internet integrado ao ensino médio. A porcentagem do curso Técnico em Agropecuária apresenta-se bastante expressiva e o motivo é que desde a sua criação, a Instituição dar prioridade às vagas da residência para os discentes desse curso.

No que tange à renda bruta mensal da família, 13 (20\%) dos indagados afirmaram ser menos de um salário mínimo; 28 (42\%) até um salário mínimo; 12 (18\%) até dois salários mínimos; 01 (1\%) até quatro salários mínimos; 01 (2\%) acima de seis salários mínimos e 11 (17\%) não souberam informar.

Tratando-se da contribuição da moradia estudantil para a permanência no curso, 62 (94\%) dos residentes afirmaram que contribui sim e 04 (6\%) disseram que não. A partir desses dados, percebemos que o Programa de Assistência Estudantil (PNAES) na ação- moradia estudantil tem atingido o objetivo de agir preventivamente nas situações de evasão escolar.

No que alude ao serviço de moradia estudantil no atendimento às necessidades estudantis, $42(64 \%)$ responderam que atende parcialmente e 24 (36\%) mencionaram que atende totalmente. Isso pode ser um reflexo do nível de compreensão dos discentes acerca do bem estar físico, mental e social vislumbrado por todo ser humano, sobretudo em uma sociedade em que os valores materiais se sobrepõem aos espirituais e as pessoas passam a ser mais exigentes.

A respeito da contribuição da moradia estudantil para o desempenho escolar, 62 (94\%) afirmaram que contribui sim e $04(6 \%)$ disseram que não. Mais uma vez essas informações confirmam o que é preconizado no Programa de Assistência Estudantil (PNAES), no sentido de contribuir para a melhoria do desempenho acadêmico do discente.

No que se refere à reprovação em alguma disciplina 
no período em que é residente, 16 (24\%) relataram que já reprovaram sim e 50 (76\%) disseram que não. Esses dados levam a crer que o estudante residente no próprio ambiente escolar disponibiliza de mais oportunidades e tempo para os estudos, contribuindo assim para sua aprovação.

Quando questionados sobre a reprovação de ano no período de residência, $03(5 \%)$ revelaram que já tinham sido reprovados e $63(95 \%)$ responderam que não. Essas informações podem reforçar a relevância que há em residir no campus, por conta das chances, tempo e oportunidades que o aluno tem para estudar, como também a ciência de que a reprovação implica perda do regime de residência.

Em se tratando do padrão das instalações físicas da moradia estudantil, 09 (14\%) afirmaram que são excelentes; $26(39 \%)$ serem boas; $27(41 \%)$ regulares; $02(3 \%)$ ruins e $02(3 \%)$ péssimas. Os dados demonstram indícios de que há necessidade de melhoria na estrutura física da residência, tendo em vista que houve uma significante porcentagem neste sentido.

Em alusão ao atendimento prestado pelos profissionais do Departamento de Assistência Estudantil (DAE), 14 (21\%) mencionaram que é excelente; 29 (44\%) bom; 16 (24\%) regular; 06 (9\%) ruim e $1(2 \%)$ péssimo. Pode-se inferir que os discentes residentes expressam uma necessidade maior do que os demais, uma vez que passam 24 horas inseridos na instituição e manifestam carências em vários aspectos, seja material, afetivo, espiritual e social.

Quando indagados sobre a possibilidade de mudar alguma coisa na moradia estudantil, algumas variáveis foram bastante expressivas, tais como: 27 (40,90\%) expressaram inserir a rede Wifi; $11(16,16 \%)$ vidro fumê nas janelas; $09(13,63 \%)$ auxílio transporte; $(10,60 \%)$ alimentação; 06 (9,09\%) camas e armários, 01 (1,51\%) mencionaram chuveiro elétrico, sala de computador, sanduicheira, espaço maior, bebedouro, jogos interativos, melhorar a paisagem externa, retirar os assistentes de alunos, mais assistência nos finais de semana, atendimento mais prestativo, segurança e estrutura física, diminuir o número de aluno no quarto; $(6,06 \%)$ disseram não mudaria nada; $(3,03 \%)$ prestação de serviço ao aluno, 03 (4,54\%) expressaram reformar os banheiros, limpeza, falta de materiais, TV e porta na sala de estudo; $(7,57 \%)$ para frigobar e geladeira.

Percebemos que a rede Wifi se sobrepõe às demais citações, demonstrando que os discentes estão cientes da necessidade de se inserirem no mundo virtual, utilizandoo para buscar conhecimento ou como um mecanismo para não se sentir excluído neste mundo sem fronteiras.

\section{CONCLUSÃO}

É válido ressaltar que parte das ações do PNAES é operacionalizada pelo Departamento de Assuntos Estudantis (DAE) do campus. Dentre essas ações, verifica-se o serviço de moradia estudantil, cujos discentes foram convidados a participarem dessa pesquisa. Em relação aos limites dos resultados alcançados nesse estudo para a construção de ações direcionadas à moradia estudantil, é possível identificar alguns registros.

Diante do exposto, consideramos que os estudantes participantes da pesquisa, em sua grande maioria consideram que a residência estudantil contribui tanto para permanência no curso, quanto para o desempenho escolar. Afirmam ainda, que a moradia atende as necessidades estudantis no padrão parcial e totalmente, o que pode ser considerado um bom serviço prestado na concepção dos estudantes.Por outro lado, os discentes apresentaram necessidades de mudança na residência, sendo bastante expressiva a inserção da rede Wifi, o que pode ser um indicativo de que a rede virtual é uma ferramenta que não pode estar à margem do percurso escolar.

A realidade encontrada demonstra que o estudante em situação socioeconômica desfavorável tem a moradia estudantil como uma forte aliada na vida escolar. Dessa forma, os alunos residentes atendidos pelo Departamento de Assistência Estudantil (DAE) podem superar sua situação de vulnerabilidade e desenvolver uma participação em busca de sua emancipação, além desse Departamento contribuir para efetivação da política de assistência estudantil nos cursos técnicos integrados ao ensino médio. Compreendemos, assim, que a assistência estudantil é um mecanismo que possibilita ao estudante condições de acesso, permanência e conclusão de seu curso, distanciando-o das estatísticas de evasão e/ou abandono escolar.

Para finalizar, ressaltamos que não temos a audaciosa pretensão de esgotar a temática, mas sim, contribuir na construção do conhecimento científico e no aperfeiçoamento institucional. Desejamos também, socializar e fortalecer a compreensão sobre a residência estudantil no processo de ensino e aprendizagem, constituindo-se em uma contribuição significativa para gestão institucional.

Além disso, apontar subsídios teóricos no que tange às possibilidades do trabalho interdisciplinar de acompanhamento sociopedagógico aos discentes beneficiados com assistência estudantil. Isso favorece a troca de conhecimento, possibilitando uma ação conjunta na resolução de conflitos e na melhoria da qualidade da educação. Por outro lado, a interdisciplinaridade é um processo, um desafio diário que está em construção. 
RESIDÊNCIA ESTUDANTIL: QUAL É A SUA EFICÁCIA NA CONCEPÇÃO DO ESTUDANTE RESIDENTE NO IFCE DO CAMPUS CRATO?

\section{REFERÊNCIAS}

\section{GIL,ANTôNIO Carlos.}

BARROSO, T. P. B. Mestrado em Educação Agrícola, Vida familiar e vida escolar: um estudo de caso sobre a trajetória escolar dos alunos internos do Centro Federal de Educação Tecnológica de Januária - MG. Seropédica, RJ: , 2008. 73 p.

BRASIL. Decreto $n^{\circ}$ 7.566, de 23 de setembro de 1909. Cria nas capitais dos estados da república escolas de aprendizes artífices para o ensino profissional primário e gratuito. Diário Oficial da União - Lei sessão 126/9/1909-pag.6975. 1996. Disponível em: <portal.mec. gov.br/seesp/arquivos/pdf/lei9394_idbn1.pdf> Acesso em: 11/01/2015.

Lei $n^{\circ}$ 9.394, de 20 de dezembro de 1996. Estabelece as Diretrizes e Bases da Educação Nacional. Brasília. 1996. Disponível em: <portal.mec.gov.br/ seesp/arquivos/pdf/lei9394_idbn1.pdf> Acesso em: $11 / 01 / 2015$

Portaria Normativa $n^{\circ} 39$, de 12 de dezembro de 2007. Institui o Programa Nacional de Assistência Estudantil (PNAES). 2007. Disponível em: <http: //portal.mec.gov.br/arquivos/pdf/portaria_pnaes.pdf> Acesso em: 31/03/2015.

Decreto $n^{o}$ 7.234, de 19 de julho de 2010. Dispõe sobre o Programa Nacional de Assistência Estudantil (PNAES). 2010. Disponível em: <http//gest ao2010. mec.gov.br/marcos_legais/decree_36.php $>$. Acesso em: 25/12/2015.

CONCEIÇÃO, J. T. História do internato: ensino agrícola federal (1934-1967). Revista de História, v. 2, n. 1, p. 80-99, 2010. Disponível em: <http//gest ao2010. mec.gov.br/marcos_legais/decree_36.php $>$. Acesso em: 25/12/2015

FEITOSA, T. d. S. Mestrado em Educação Agrícola, As "reformas" do ensino profissionalizante de 1996 a 2006 na escola Agrotécnica Federal de Crato Ceará: acomodação à legislação ou consciência da prática? Seropédica, RJ: , 2010. 89 p.

FOUCAULT, M. Vigiar e punir: nascimento da prisão. tradução de raquel ramalhete. Vozes, Petrópolis, Rio de Janeiro, 2009.

GIL, A. C. Métodos e técnicas de pesquisa social. Atlas. 4. ed. São Paulo: , 1994.
GOFFMAN, E. Manicômios, prisões e conventos. São Paulo: Perspectiva, 2008.

IFCE. Instituto Federal de Educação Ciência e Tecnologia do Ceará. plano de desenvolvimento institucional 2014-2018. Crato, CE, 2013.

OTRANTO, C. R. A política de educação profissional do governo lula. Anais da $34^{\circ}$ Reunião Anual da Associação Nacional de Pós-Graduação e Pesquisa em Educação, Natal:[ANPEd], p. 1-17, 2011. Disponível em: <http://34reuniao.anped.org.br/images/trabalhos/ GT11/GT-315\%20int.pdf> Acesso em: 13/02/2013.

PACHECO, E. Institutos Federais: uma revolução na educação profissional e tecnológica. São Paulo: Fundação Santillana, Moderna, 2011. 13-32 p.

PELLA, J. J. Mestrado em Educação Agrícola, Cursos Superiores de Tecnologia no CEFET - ES: implantação e perspectivas. Seropédica, RJ: UNIVERSIDADE FEDERAL RURAL DO RIO DE JANEIRO, 2005. 71 p.

SOBRAL, F. J. M. Retrospectiva histórica do ensino agrícola no brasil. Revista Brasileira da Educação Profissional e Tecnológica, v. 2, n. 2, p. 78-95, 2009.

SOUSA, A. S. d. Mestrado em Linguística Aplicada, $O$ ensino de língua espanhola no Instituto Federal de Brasília: o dito, o feito e o pretendido. Brasília: , 2013. 120 p. Disponível em: <repositório.unb.br/bitstreams/ 10482/15516/1/20016_AlessandraSilvadeSousa.pdf> Acesso em: 10/10/2016.

WERMELINGER, M.; MACHADO, M. H.; AMÂNCIO FILHO, A. Políticas de educação profissional: referências e perspectivas. Ensaio: Avaliação e Políticas Públicas em Educação, Fundação Cesgranrio, v. 15, n. 55, 2007. 